\title{
Estudo clínico e histopatológico da reação tecidual às suturas interna e externa dos fios monofilamentares de nylon e poliglecaprone 25 em ratos ${ }^{1}$
}

\author{
Clinical and histopathological study of tissue reactivity to monofilament suture \\ materials: nylon and poliglecaprone 25 in rats
}

\author{
Camila Maria Beder Ribeiro², Valdemiro Amaro da Silva Júnior ${ }^{3}$, Joaquim Celestino da Silva Neto ${ }^{4}$, Belmiro Cavalcanti \\ do Egito Vasconcelos ${ }^{5}$
}

1. Trabalho realizado na Disciplina de Morfologia e Fisiologia Animal da Universidade Federal de Pernambuco, Recife-PE.

2. Aluna da Graduação da Faculdade de Odontologia de Pernambuco/Universidade de Pernambuco, Bolsista do PIBIC/CNPq Brasil.

3. Professor Adjunto do Departamento de Morfologia e Fisiologia Animal - Área: Histologia, Universidade Federal Rural de Pernambuco.

4. Professor Departamento de Ciências Morfológicas - Instituto de Ciências Biológicas/Universidade de Pernambuco, Aluno do Doutorado em Cirurgia e Traumatologia Buco-Maxilo-Facial da Faculdade de Odontologia de Pernambuco, Universidade de Pernambuco.

5. Orientador e Coordenador da Pesquisa, Professor Adjunto da Faculdade de Odontologia de Pernambuco, Universidade de Pernambuco, Coordenador do Mestrado e Doutorado em Cirurgia e Traumatologia Buco-Maxilo-Facial da Faculdade de Odontologia de Pernambuco/ Universidade de Pernambuco.

\begin{abstract}
RESUMO
Objetivo: Neste estudo realizamos a análise clínica e histopatológica da reação tecidual dos fios de nylon e poliglecaprone 25 monofilamentares nas suturas interna e externa em ratos. Métodos: Foram utilizados 40 Rattus norvegicus (Wistar) machos. $\mathrm{O}$ ato operatório consistiu de incisão e divulsão dos planos muscular e cutâneo realizadas na região posterior das coxas dos animais. As suturas internas e externas da coxa direita foram realizadas com o fio de nylon n ${ }^{\circ} 5-0$, e na coxa esquerda aplicamos o poliglecaprone $25 n^{\circ} 5-0$. Os animais foram divididos em 4 grupos (n=10) de acordo com o tempo pósoperatório G1 (7 dias), G2 (14 dias), G3 (21 dias) e G4 (28 dias). Para a avaliação cínica foi considerada a ocorrência de deiscência, de exsudato e edema. Na análise histopatológica objetivou-se avaliar reação inflamatória, células gigantes de corpo estranho, proliferação fibroblástica e fibrose. Resultados: Clinicamente, não foram observadas alterações nos grupos estudados. Histopatologicamente a reação inflamatória, presença de células gigantes de corpo estranho, proliferação fibroblástica e fibrose foram maiores nas suturas internas realizadas com Nylon. Nas suturas realizadas com poliglecaprone 25 essa reação declinou com o passar do tempo pós-operatório. Conclusões: De acordo com a metodologia empregada podemos concluir que as suturas externas realizadas com nylon induziram menor reação tecidual, enquanto que nas suturas internas este fio contribuiu para perpetuar a reação tecidual. As suturas externas realizadas com poliglecaprone 25 apresentaram maior reação tecidual, e suturas internas realizadas com o mesmo fio a reação tecidual declinou na medida em que o fio estava sendo absorvido.
\end{abstract}

Descritores: Nylon. Poliglecaprone 25. Reação tecidual.

\begin{abstract}
Purpose: The aim of this experimental study was to evaluate through a clinical and histopatological analysis the tissue reactivity caused by two monofilament sutures nylon and poliglecaprone 25 on the internal and external sutures in rats. Methods: For this study, we used forty male Rattus novergicus (Wistar rats). The experimental procedures were incisions and divulsions performed on the back of the animals' thighs. Internal and external sutures were done on the right thigh using nylon 0-5, and on the left thigh using poliglecaprone 25 -5. The animals were distributed in 4 groups of 10 rats, according postoperatory period on the 7, 14, 21 and 28 days, G1 ( $7^{\text {th }}$ day), G2 (14 ${ }^{\text {th }}$ day), G3 (21 $1^{\text {th }}$ day) and G4 (28 $8^{\text {th }}$ day). The clinical assentment aimed to verify the existence of deiscence, exsudate and edema. The histopathologic analisy's was intended to eveluate the inflammatory reaction, foregin body giant cells, fibroblastic proliferation and fibrosis. Results: Clinically, no changes were found on groups studied. Histopathological analysis inflammatory reaction, foregin body giant cells, fibroblastic proliferation and fibrosis were higher on the internal sutures with nylon. On the sutures done with poliglecaprone 25 showed an increase in tissue reactivity passing postoperatory period. Conclusions: On the basis of the methodology used in the study, it was concluded that external sutures done with nylon produce less tissue reactivity; on internal sutures, however, this material contributes to the maintenance of the tissue reaction. The external sutures done with poliglecaprone 25 showed a greater tissue reaction; on the external sutures the tissue reaction decreased while the thread was being absorbed.
\end{abstract}

Key words: Nylon. Poliglecaprone 25. Tissue Reactivity. 


\section{Introdução}

Define-se sutura como uma manobra cirúrgica que visa restituir a integridade dos tecidos que foi rompida por traumas ou intervenções cirúrgicas. Esta manobra é de fundamental importância, no sentido de favorecer a evolução da ferida cirúrgica pela imobilização de tecidos, por reduzir espaços anatômicos, criar condições de estabilização do coágulo, impedir a entrada de microrganismos nos tecidos mais profundos, auxiliar na hemostasia, manter a funcionalidade e também pela estética ${ }^{1}$.

A sutura da ferida é o passo final da maioria dos procedimentos cirúrgicos envolvendo uma incisão ou laceração. Manobras cirúrgicas especializadas são necessárias para o fechamento da ferida e precisam ser selecionadas cuidadosamente tendo em vista que esta importante etapa prepara a ferida para facilitar o processo de cicatrização ideal. Para tanto, a sutura confere o restabelecimento da continuidade tecidual, minimização do tamanho da cicatriz e restauração da função².

Estudos experimentais ${ }^{3}$ mostraram que a infecção de uma ferida operatória está em direta relação com a presença de corpos estranhos na região. Embasados na idéia de que o próprio fio poderia ser um corpo estranho ao tecido vivo, os autores passaram a estudar as características físicas e químicas de cada fio na dependência de sua estrutura básica. Os resultados obtidos através da metodologia empregada pelos autores mostraram que reação tecidual provocada pelo fio é proporcional ao seu diâmetro e por isso, deve-se utilizar o fio com o menor diâmetro possível nas suturas e ligaduras. As suturas são feitas com uma ampla variedade de materiais e cada um designado com um propósito particular. Os dois tipos básicos de materiais de sutura são absorvíveis, que não requerem remoção; e não absorvíveis, que necessitam de remoção, ambos podendo apresentar-se sob as formas monofilamentada ou multifilamentada ${ }^{2}$.

Na literatura há uma divergência de opiniões entre os autores em relação ao melhor material de sutura. No entanto, todos os autores são unânimes em afirmar que devem promover uma boa aproximação dos tecidos devendo a síntese ser atraumática. Atualmente existem pesquisas constantes por materiais e métodos de síntese que sejam biocompatíveis, de fácil manipulação, previnam infecção e que promovam um melhor reparo da ferida ${ }^{1}$.

Foi realizada uma revisão da literatura sobre a introdução do poliglecaprone 25 e a existência de uma preocupação sobre a natureza multifilamentar dos fios de sutura absorvíveis sintéticos disponíveis no mercado, tais como a poligalactina 910, por causarem elevada reação tecidual, traumatismos aos tecidos e aumentarem a capilaridade bacteriana no interstício dos filamentos. Então, com a introdução de fios monofilamentares sintéticos houve uma diminuição destas preocupações ${ }^{4}$.

O poliglecaprone 25 é um fio monofilamentar sintético à base blocos segmentados de copolímeros de epsilon coprolactona e glicolida que são absorvidos por hidrólise quando em contato com organismos vivos ${ }^{5,6,7}$. A sua absorção é completa entre 91 e 119 dias após implantação. Apresenta excelente resistência tênsil, reduzida memória e grande maneabilidade. Este material apresenta uma perda da sua resistência tênsil de 20 a 30 \% após duas semanas de pós-operatório (período considerado crítico na cicatrização e reparação de tecidos). Devido a estas características pode ser aplicado não somente a suturas internas, mas também em suturas superficiais de mucosa e externas cutâneas ${ }^{4}$.

O nylon é um material sintético, monofilamentar derivado de poliamidas que se caracteriza pela elasticidade devido a sua resistência mecânica. É freqüentemente utilizado para a síntese da pele e produz baixa reatividade tecidual $^{8}$. Dessa forma, nesta pesquisa, nos propusemos a avaliar a reação tecidual dos fios monofilamentares sintéticos de nylon e de poliglecaprone 25 haja vista serem dois tipos de materiais de sutura largamente utilizados em atos operatórios.

\section{Métodos}

Para a realização deste estudo foram utilizados 40 Rattus norvegicus (Wistar) machos procedentes dos mesmos genitores e oriundos do Biotério da Universidade Federal Rural de Pernambuco. Os animais foram submetidos a um período de quarentena e confinamento para adaptação às condições experimentais e vermifugados contra endo e ectoparasitas (Mebendazol e Ivermectina).

Todos os espécimes tinham completado 90 dias de vida e pesavam entre $170 \mathrm{~g}$ e $250 \mathrm{~g}$ no momento do ato cirúrgico. Os animais permaneceram em gaiolas, sendo 05 por unidade, onde receberam água mineral e ração hiperprotéica sólida (LABINA ${ }^{\circledR}$ PURINA) ad libitum.

Após serem submetidos a jejum hídrico e alimentar por 12 horas antes da cirurgia os animais foram pesados e a anestesia geral foi realizada com Cloridrato de Quetamina e o Cloridrato de Xilazina, diluídos 1:1 na dose de 0,1mg/100g através da via intraperitonial.

Os animais foram posicionados em decúbito dorsal para a realização da tricotomia manual. Foi realizada anti-sepsia com polivinilidopirrolidona na região compreendida entre o dorso e coxas direita e esquerda e em seguida os campos estéreis foram aposicionados. Imediatamente após esta etapa foi efetuada a incisão linear de $15 \mathrm{~mm}$ de extensão com bisturi convencional lâmina ${ }^{\circ} 15$.

Após esta etapa, os animais foram submetidos à dissecção cirúrgica dos planos cutâneo e muscular com tesoura (ÍRES), e divulsão dos músculos vasto lateral e bíceps femural com pinça hemostática curva (HALSTED). Os planos muscular e cutâneo foram suturados através da utilização dos fios monofilamentares de nylon $n^{\circ}$ 5-0 (MONONYLON ${ }^{\circledR}$ Somerville) na coxa direita, e poliglecaprone $25 n^{\circ} 5-0$ (MONOCRYL ${ }^{\circledR}$ Ethicon) na coxa esquerda. A amostra foi dividida em 4 grupos de 10 animais (Grupo 1 ou G1, Grupo 2 ou G2, Grupo 3 ou G3 e Grupo 4 ou G4). Em todos os grupos os animais foram submetidos ao procedimento cirúrgico descrito anteriormente, e foram sacrificados após 7 (Grupo 1), 14 (Grupo 2), 21 (Grupo 3) e 28 (Grupo 4) dias do ato operatório. O sacrifício foi realizado com a utilização de dose letal do anestésico geral Pentoberbital Sódico (Tiopental ${ }^{\circledR}$ ).

Para a descrição dos resultados observados clinicamente foram examinadas as suturas externas nos $7^{\circ}$, $14^{\circ}, 21^{\circ}$ e $28^{\circ}$ dias de pós-operatórios e os seguintes eventos foram considerados: deiscência da sutura, presença de 
exsudato (purulento-seroso ou sanguinolento) e edema. As peças cirúrgicas foram retirados com o mínimo de traumatismo e fixados em solução de formol a $10 \%$, encaminhados ao Laboratório de Patologia da Universidade Federal Rural de Pernambuco, processados e incluídos em parafina para a realização de cortes semi-seriados transversais de $5 \mathrm{~mm}$. As seções foram coradas pela coloração de rotina com Hematoxilina-Eosina (H. E).

A avaliação histopatológica foi realizada sob microscopia de luz em um aumento de $10 \mathrm{X}$ para a visualização panorâmica da lâmina e caracterização do padrão de reação tecidual em intensa, moderada e discreta; e um aumento de 40X para visualização dos detalhes da reação dos tipos e eventos celulares presentes; foram anotados os eventos de reação inflamatória, células gigantes de corpo estranho, proliferação fibroblástica, fibrose e regressão do tecido de granulação. O granuloma de corpo estranho foi considerado quando na ocorrência de macrófagos multinucleados, linfócitos e eventualmente plasmócitos. A proliferação de tecido conjuntivo fibroso no segmento cutâneo e muscular foi considerada fibrose. Presença de infiltrado inflamatório na derme e na intimidade do músculo foi considerada reação inflamatória. A metodologia da análise estatística foi descritiva a partir dos dados observados e coletados no experimento. O presente estudo foi submetido ao Comitê de Ética em Pesquisa da Universidade de Pernambuco, tendo sido aprovado sob o número 067/03, estando o mesmo em consonância com as boas práticas de pesquisa com animais e coerente com a Declaração Universal dos Direitos dos Animais (UNESCO, 1978).

\section{Resultados}

Na descrição dos resultados foram consideradas todas as áreas das suturas externas e internas próximas ao material de sutura empregado em todos os períodos de tempo avaliados.

\section{Avaliação clínica}

Clinicamente em nenhuma das suturas apresentou eventos como edema ou deiscência da sutura para todos os grupos estudados.

\section{Avaliação histopatológica (Figura 1 e Tabela 1)}

Na análise histopatológica a reação inflamatória esteve mais presente nas suturas externas realizadas com PG 25 nos grupos G1 (Figura 02) 100\% e G2 (Figura 03) 80\%. Entretanto, nos grupos G3 (Figura 04) e G4 (Figura 05) ocorreu a diminuição desta reação nestas suturas realizadas com o fio de Poliglecaprone 25 (10\% para os dois grupos). Nas suturas internas do G1 observou-se o mesmo padrão de reação inflamatória para o nylon e poliglecaprone 25 (100\%); no grupo G2 as suturas internas e com poliglecaprone 25 foram menos reativas (60\%); nos grupos G3 e G4 as suturas internas realizadas com nylon foram menos reativas (30\% e 60\%) do que as suturas com poliglecaprone 25 (G3: 60\% e G4: 80\%). A presença de células gigantes de corpo estranho foi maior nas suturas externas e internas realizadas com nylon nos grupos G1 e G4 (10\%, 40\%; 20\%,40\%).

A proliferação fibroblástica, que acompanhou a fibrose, regrediu com evolução do processo cicatricial nas suturas realizadas com poliglecaprone 25 e aumentou nas suturas realizadas com nylon. A fibrose foi mais elevada nas suturas externas e internas realizadas com poliglecaprone 25 nos grupos G1, G2 e G3 (70\% e 60\%; 40\% e 50\%; 90\% e 80\% respectivamente). As suturas externas e internas realizadas com o fio de nylon apresentaram resultados superiores no grupo G4 (80\% e 60\% respectivamente). A formação de tecido de granulação foi maior nas suturas externas e internas realizadas com nylon em todos os grupos (G1; G2; G3 e G4); e a regressão do tecido de granulação foi evidenciada a partir do $14^{\circ}$ dia (G2), com resultados melhores nas suturas externas realizadas com o fio de nylon (60\%).

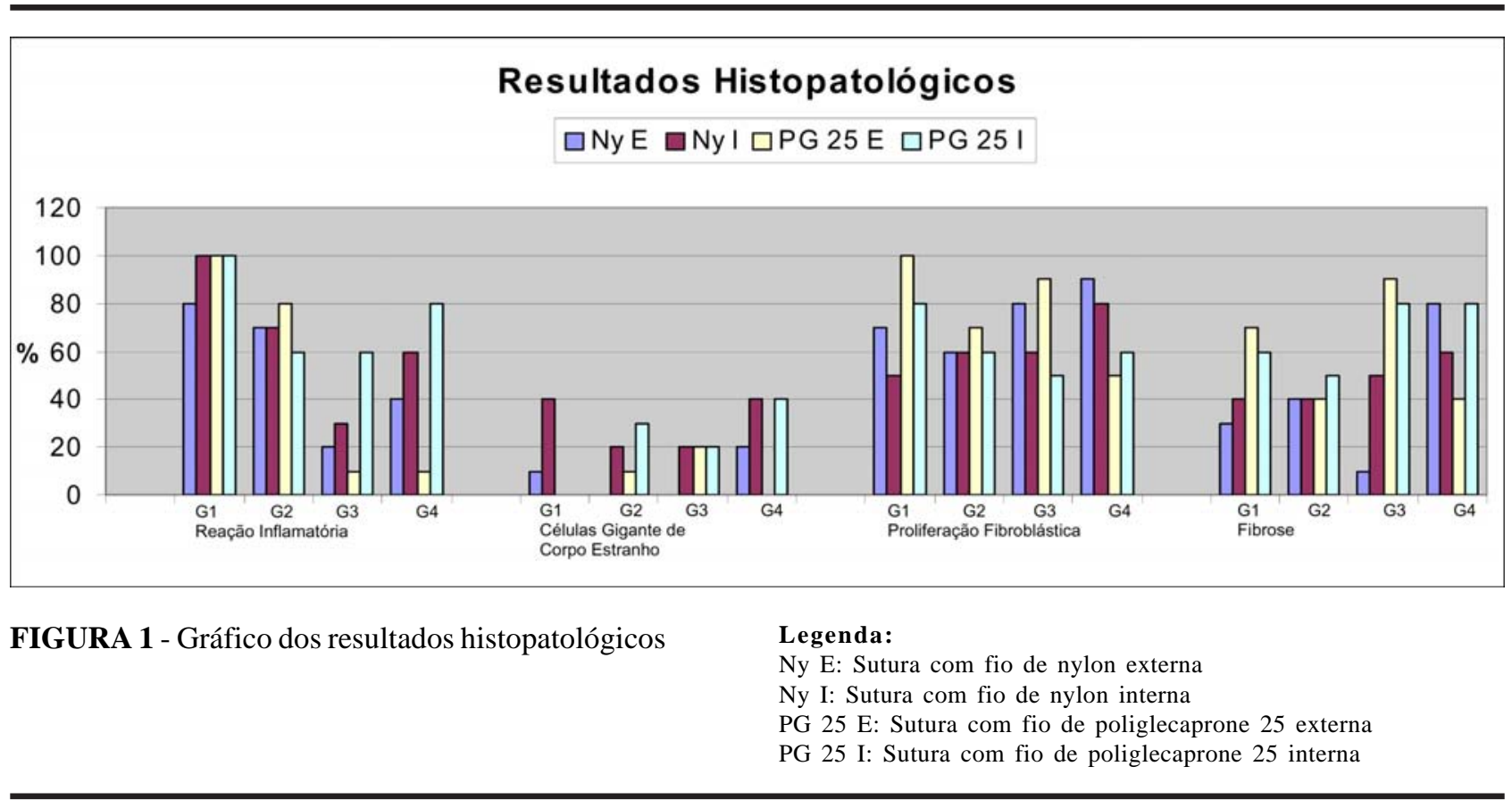


TABELA 1 - Resultados histopatológicos

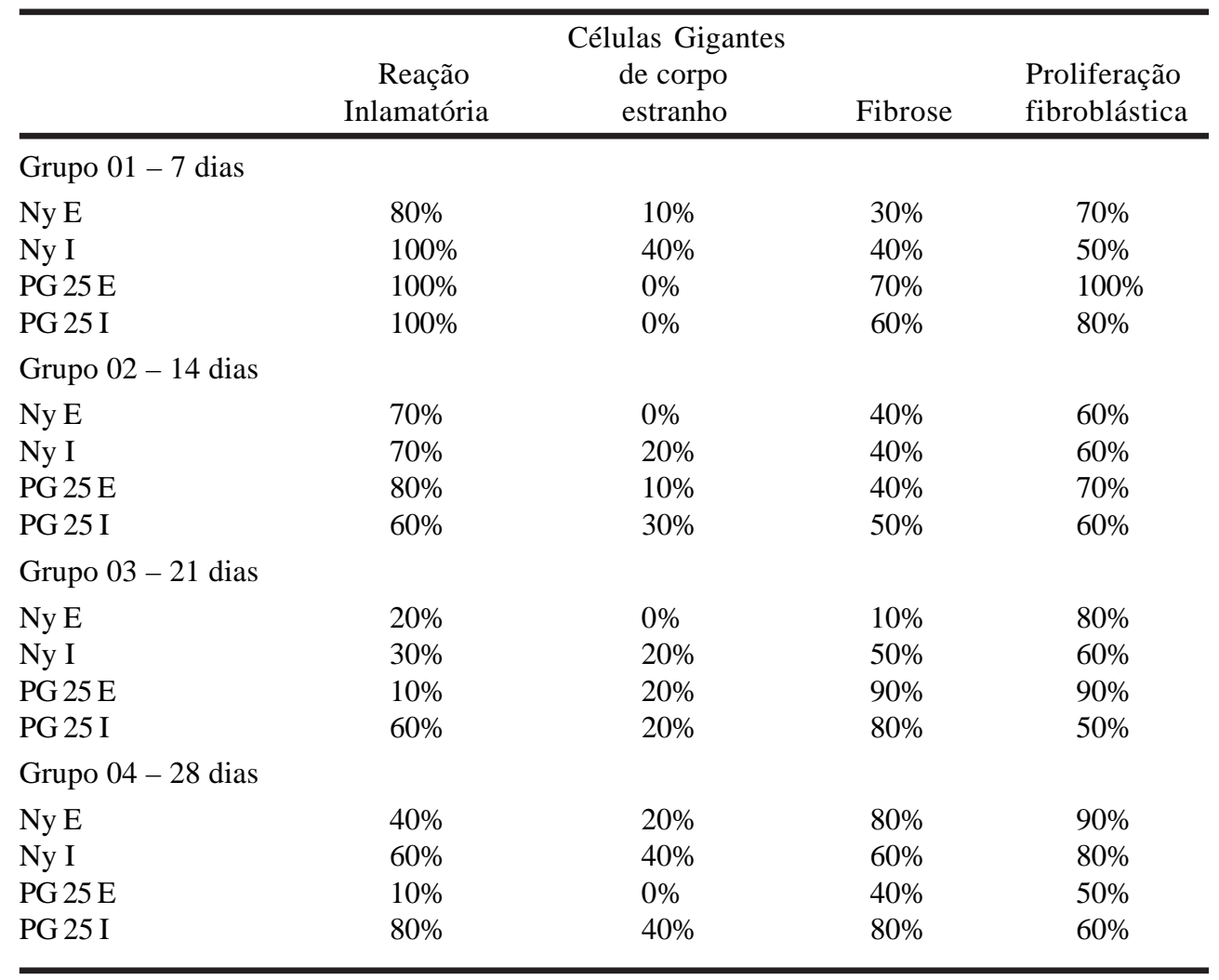

\section{Legenda:}

Ny E: Sutura com fio de nylon externa.

Ny I: Sutura com fio de nylon interna.

PG 25 E: Sutura com fio de poliglecaprone 25 externa.

PG 25 I: Sutura com fio de poliglecaprone 25 interna.

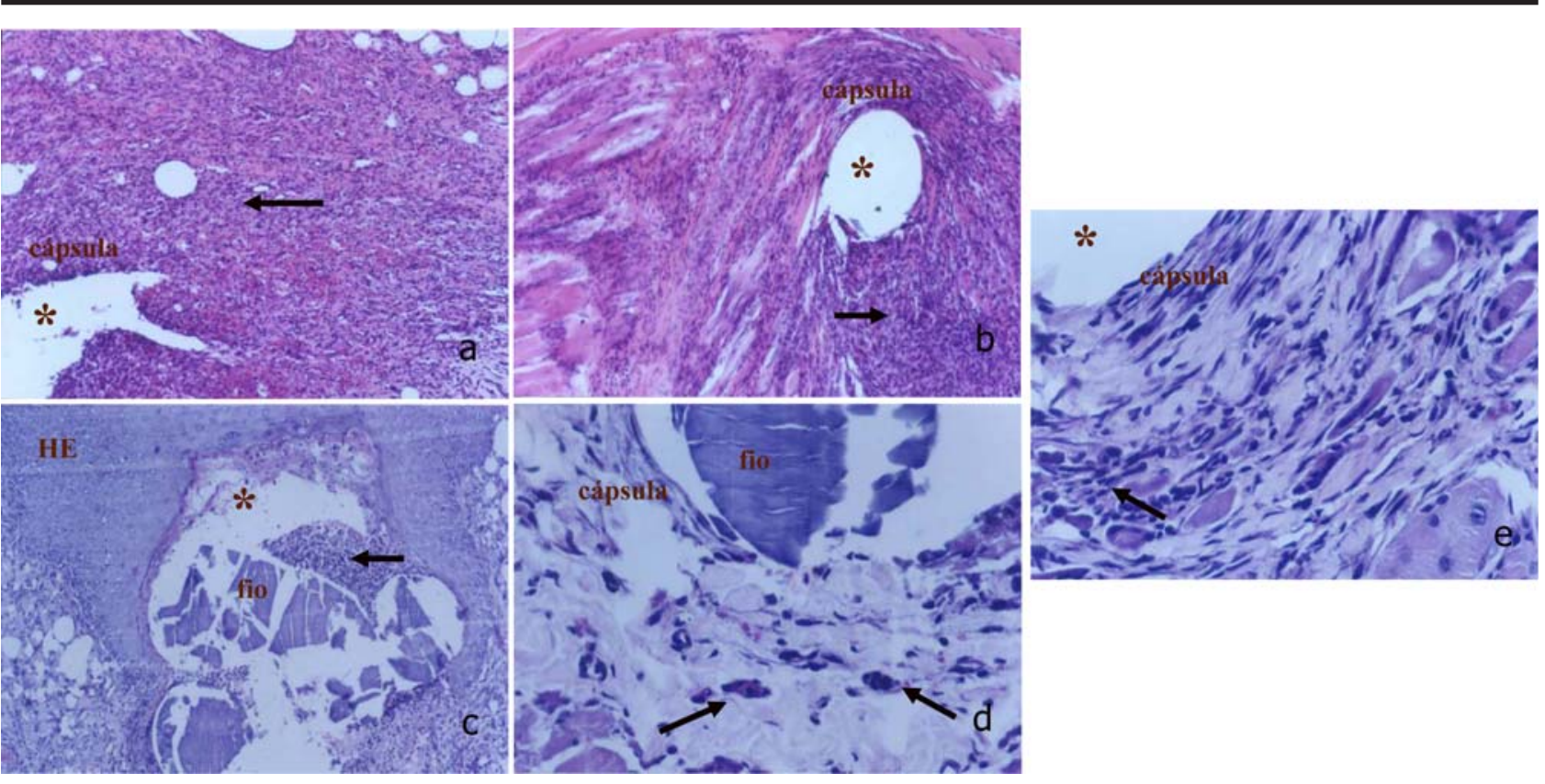

FIGURA 2 - Aspecto histopatológico do grupo 01 (07 dias de pós-operatório)

\section{Legenda:}

a.Nylon: Sutura externa. Reação de encapsulamento, cavidade do fio $\left(^{*}\right)$, reação inflamatória (seta), proliferação fibroblástica, formação de tecido de granulação e hemorragia. Aumento 10x; b.Nylon: Sutura interna. Reação de encapsulamento, cavidade do fio (*), proliferação fibroblástica, reação inflamatória intensa (seta); Aumento 10x; c.PG 25: Sutura externa. Presença de proliferação fibroblástica, cavidade do fio $(*)$, hiperplasia epidérmica ao redor do fio (HE), reação inflamatória intensa (seta), presença de fio; Aumento 10x; d.PG 25: Sutura interna. Reação de encapsulamento, presença de células inflamatórias (seta), presença de fio; Aumento 40x; e.PG 25: Sutura interna. Detalhe da cápsula - proliferação fibroblástica e fibrose, cavidade do fio $\left(^{*}\right)$, presença de células inflamatórias (seta); Aumento 40x. 


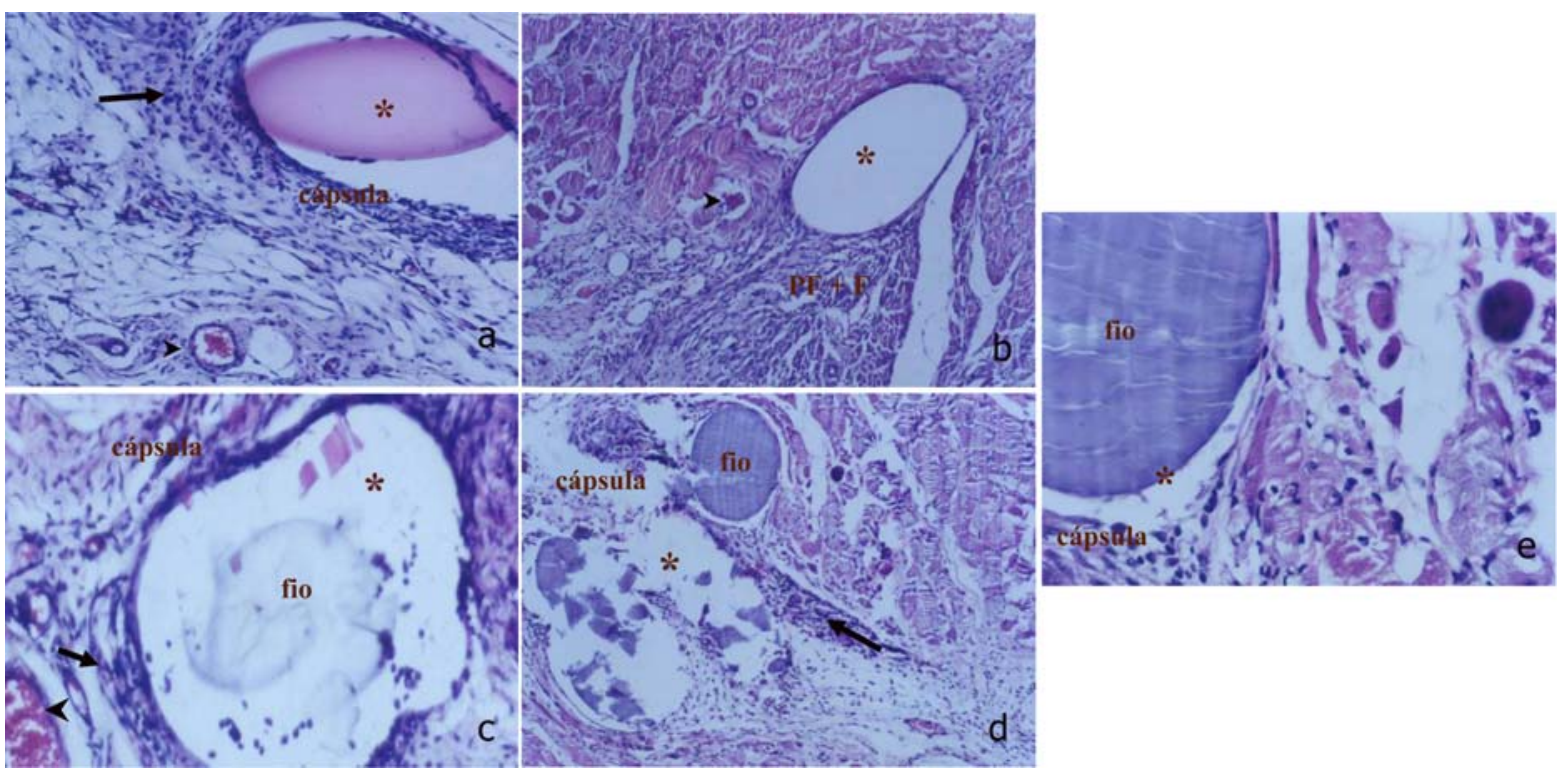

FIGURA 3 - Aspecto histopatológico do grupo 02 (14 dias de pós-operatório)

Legenda:

a.Nylon: Sutura externa. Reação de encapsulamento, cavidade do fio com exsudato protéico (*), proliferação fibroblástica, fibrose, reação inflamatória, células inflamatórias (seta), formação de tecido de granulação, vasos congestos $(\rightarrow$ ); Aumento 10x;

b.Nylon: Sutura interna. Reação de encapsulamento, cavidade do fio $(*)$, proliferação fibroblástica e fibrose (PF + F), reação inflamatória, vasos congestos $(\rightarrow)$; Aumento 10x;

c.PG 25: Sutura externa. Reação de encapsulamento, cavidade do fio $\left(^{*}\right)$, proliferação fibroblástica, fibrose, reação inflamatória (seta), vasos congestos $(\rightarrow)$, presença do fio; Aumento 10x;

d.PG 25: Sutura interna. Reação de encapsulamento, cavidade do fio $(*)$, intensa proliferação fibroblástica, fibrose, reação inflamatória (seta), vasos congestos $(\rightarrow$ ), presença do fio; Aumento 10x;

e.PG 25:Detalhe sutura interna; Aumento 40x.

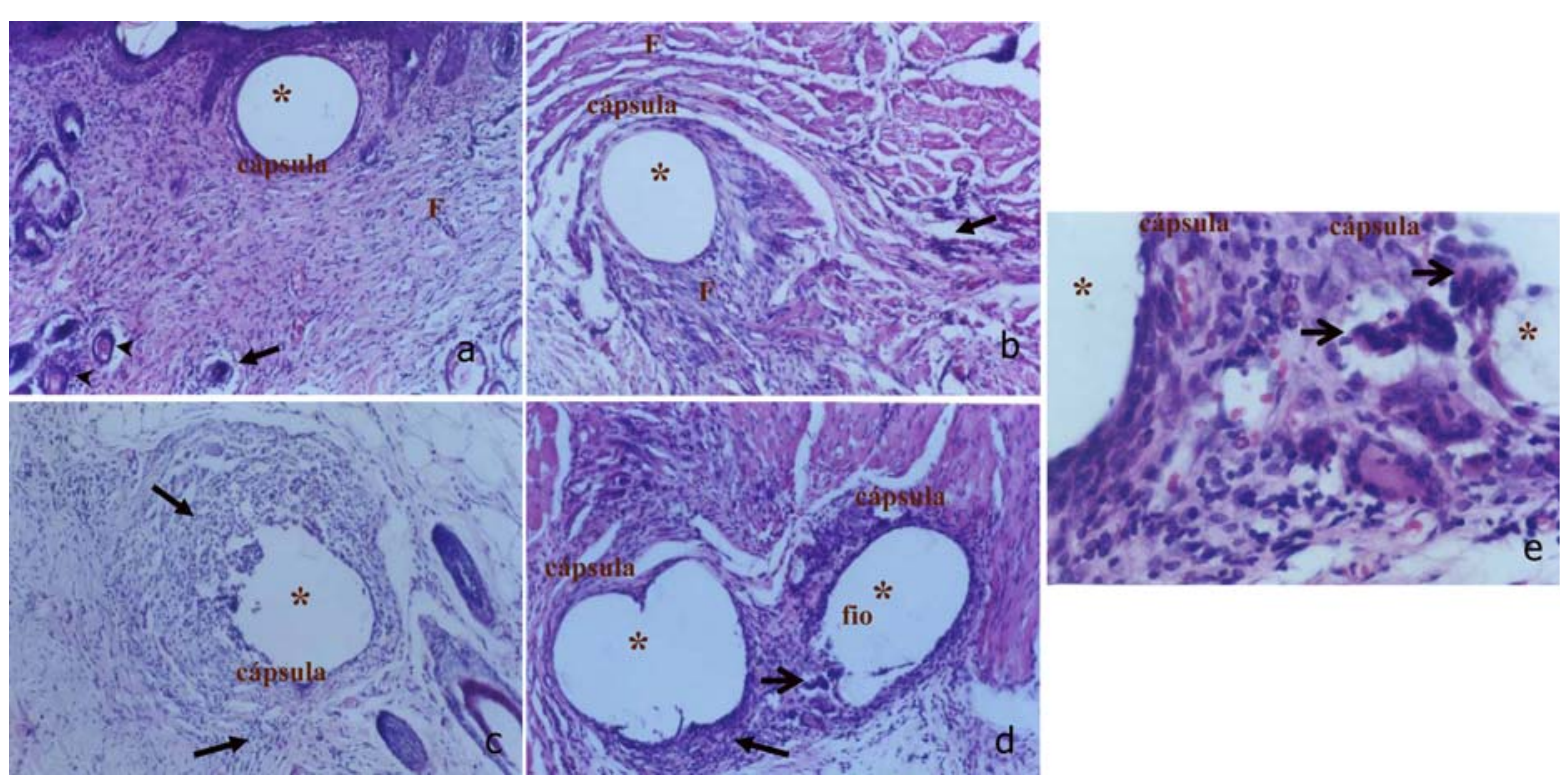

FIGURA 4 - Aspecto histopatológico do grupo 03 (21 dias de pós-operatório)

\section{Legenda:}

a.Nylon: Sutura externa. Reação de encapsulamento, cavidade do fio $(*)$, intensa proliferação fibroblástica, fibrose $(\mathrm{F})$, reação inflamatória focal no tecido subcutâneo (seta); Aumento 10x;

b.Nylon: Sutura interna. Reação de encapsulamento, intensa proliferação fibroblástica, fibrose (F), células inflamatórias de permeio (seta), vasos congestos $(\rightarrow$ ); Aumento 10x;

c.PG 25: Sutura externa. Reação de encapsulamento, proliferação fibroblástica, fibrose, reação inflamatória(seta), ausência do fio; Aumento 10x;

d.PG 25: Sutura interna. Reação de encapsulamento, proliferação fibroblástica, fibrose, reação inflamatória intensa (seta), células gigantes de corpo estranho $(\rightarrow)$, presença do fio; Aumento 10x;

e.PG 25: Sutura interna. Detalhe: presença de células gigantes de corpo estranho( $\rightarrow$ ); Aumento 40x. 

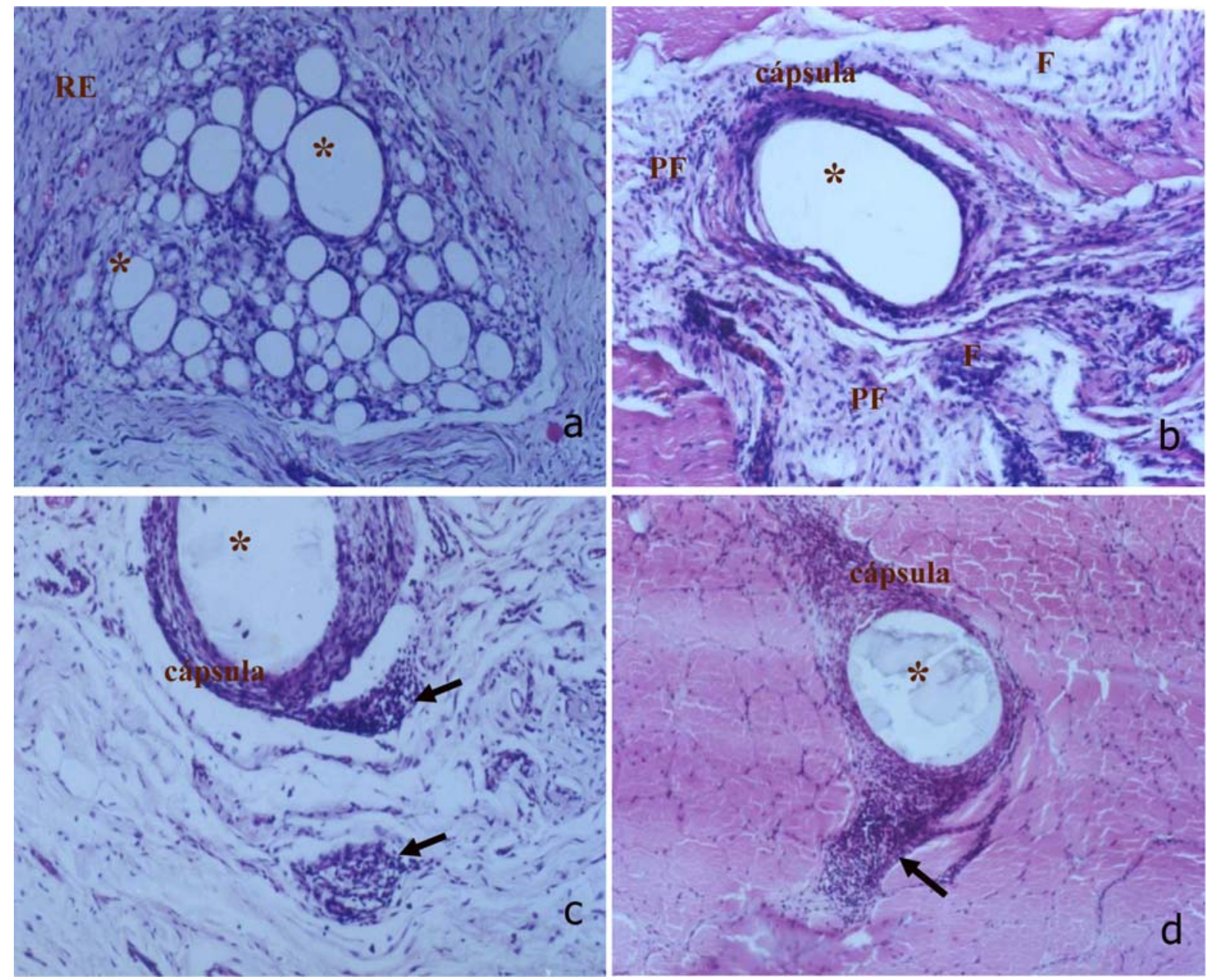

FIGURA 5 - Aspecto histopatológico do grupo 04 (28 dias de pós-operatório)

\section{Legenda:}

a.Nylon: Sutura externa. Reação de vários encapsulamentos (RE), proliferação fibroblástica, fibrose, reação inflamatória; Aumento 4x; b.Nylon: Sutura interna. Reação de encapsulamento, proliferação fibroblástica (PF), fibrose (F), reação inflamatória discreta, vasos congestos; Aumento 10x;

c.PG 25: Sutura externa. Reação de encapsulamento, fibrose, reação inflamatória focal (seta), presença do fio sendo absorvido; Aumento $10 \mathrm{x}$;

d.PG 25: Sutura interna. Reação de encapsulamento, fibrose moderada, reação inflamatória intensa e fagocitária (MN) (seta), fio sendo absorvido; Aumento 10x.

\section{Discussão}

A reação tecidual às suturas inicia-se com o trauma da passagem da agulha e do fio, porém a reação ao fio propriamente dita aparece entre o segundo e o sétimo dia após sua implantação ${ }^{3}$. Baseado neste achado da literatura, no nosso estudo as avaliações clínicas e histopatológicas foram realizadas a partir do sétimo dia pós-operatório. É evidente a superioridade dos fios sintéticos sobre aqueles de origem orgânica sob os aspectos de reação tecidual, aderência bacteriana, coeficiente de atrito, resistência tênsil, capilaridade e absorção de fluidos. Dentre os fios sintéticos, o de nylon é o que apresenta melhor biocompatibilidade ${ }^{9,10}$. Devido às características do material e o fato de ser monofilamentar, apresenta vantagens quanto à capilaridade e absorção de fluidos além de um baixo coeficiente de atrito. O fio de nylon provoca uma reação inflamatória de pequena extensão e por tempo limitado; e nas suturas profundas provoca reações do tipo corpo estranho. A proliferação de fibroblastos e capilares sanguíneos é mais precoce nos locais em contato com o fio ${ }^{11}$. Através da metodologia empregada em nosso estudo corroboramos com os autores que suturas realizadas com o fio de nylon apresentaram eventos de proliferação fibroblástica e neoformação vascular mais precocemente, porém estes eventos não regrediram com o passar do tempo pós-operatório. Estudos prévios revelaram que o nylon é um material que permanece estruturalmente inalterado, porém quanto aos eventos histopatológicos ocorridos nos tecidos adjacentes ao fio observou-se no primeiro dia presença de fibroblastos e novos capilares sanguíneos, aumentando bastante no terceiro dia, e no sétimo dia observou-se um tecido conjuntivo bem desenvolvido envolvendo o fio, além da presença de células gigantes ${ }^{12}$. Este mesmo padrão de reação tecidual foi observado nos resultados obtidos no grupo 1 (7 dias) do nosso estudo. Os resultados dos grupos 2 (14 dias), 3 (21 dias) e 4 (28 dias), do nosso estudo não puderam ser comparados em decorrência de não ter sido estudado pelos 
referidos autores. Foram realizados estudos para a avaliação histológica e reparo da pele de suínos em suturas com fio de nylon. Através da metodologia empregada pelos autores, seus resultados revelaram que o nylon que além de necessitar remoção, é um fio traumático desde a penetração da agulha nos tecidos cutâneos e subcutâneos até à inserção do próprio material estranho ao organismo. Este material ocasiona uma reação inflamatória maior resultando na epitelialização do trajeto do fio de sutura pelos tecidos com invaginação das bordas da ferida e a persistência por vários dias da crosta sangüínea ${ }^{1}$. De acordo com os resultados obtidos em nossos estudos, o fio de nylon mantém elevada presença de fibroblastos ativos secretando matriz de colágeno, o que caracteriza uma proliferação fibroblástica acompanhada de fibrose em todos os grupos estudados. $\mathrm{O}$ fio de poliglecaprone 25, além de ser um fio que não necessita remoção, é um material que oferece conforto para o paciente nas suturas externas. Os autores puderam concluir que o fio de poliglecaprone 25 é um bom fio para suturas externas (contínuas em pele), oferece uma boa hemostasia, possui um pequeno risco de infecção e sua cicatriz é discreta ${ }^{4}$. De acordo com os resultados obtidos na avaliação clínica do nosso estudo, o poliglecaprone 25 ofereceu boa hemostasia, haja vista nenhum dos animais do estudo apresentou hemorragia. Em estudos in vivo revelaram que a implantação do fio apresentou mínima resistência de passagem através dos tecidos acompanhada de uma discreta ou mínima reação tecidual $^{4}$. De acordo com a metodologia empregada os resultados obtidos no nosso estudo não foram concordes com os dos autores, pois a reação tecidual que foi observada variou de moderada a intensa, porém declinou com o passar do tempo pós-operatório. Estudos realizados sobre resposta tecidual em região subcutânea de ratos frente aos fios de sutura de poliglecaprone 25, poligalactina 910 e politetrafluoretileno, revelaram que o fio de poliglecaprone 25 induziu um menor reação inflamatória, seguida pelos fios de poligalactina 910 e politetrafluoretileno, respectivamente ${ }^{7}$. Os resultados obtidos no nosso trabalho revelaram que o padrão da reação tecidual das suturas realizadas com poliglecaprone 25 variou de moderada à intensa, devido à presença de muitas células inflamatórias e fibroblastos ativos. Contudo, foi observado que o padrão da reação tecidual das suturas realizadas com o fio de poliglecaprone 25 declinou com o passar do tempo pósoperatório contrastando com a visível manutenção destes eventos nas suturas realizadas com o nylon. Foi realizado um estudo comparativo da biocompatibilidade de três fios de sutura monofilamentares (Polidioxanone, Poliglecaprone 25 e Glicomer 631). Baseados em seus resultados, os autores concluíram que o fio de Poliglecaprone 25 apresentou valores de reação tecidual mínimo ${ }^{14}$, concordando com os achados de outros estudos sobre este fio ${ }^{4}$. No entanto, em nosso estudo, o padrão da reação inflamatória e tecidual do fio de poliglecaprone 25 observado foi elevado, porém declinou à medida que o fio estava sendo absorvido. Concordamos com os autores que o poliglecaprone 25 é um bom material para suturas internas, decorrida sua absorção não mantém elevados índices de reação tecidual, como observado no $28^{\circ}$ dia de pós-operatório, que revelou um declino na proliferação fibroblástica, fibrose e reação inflamatória focais e restritas à área do fio. Porém, cabe a nós ressaltar, no entanto que o fio de poliglecaprone 25 ainda é um fio de uso restrito devido ao seu elevado custo. Proporcionalmente, a unidade desse fio quando comparada à unidade do fio de nylon custa cerca de 11 vezes mais. Suturas realizadas com o poliglecaprone 25 demonstraram que este material possui excelentes propriedades de maneabilidade e pouca memória, o que confere ao fio um nó resistente ${ }^{4}$. Entretanto, ensaios laboratoriais revelaram que o fio de poliglecaprone 25 possui um nó pouco resistente $\mathrm{e}^{15}$. Durante a etapa experimental da nossa pesquisa, pudemos observar que as suturas realizadas com poliglecaprone 25 apresentaram nós pouco resistentes, o que sugeriu que este fio apresenta uma boa memória, conseqüentemente, um nó pouco seguro. A maneabilidade deste material foi dificultada pela sua coloração transparente. Através de um questionário para avaliar a longevidade de suturas absorvíveis no meio bucal foi realizado um estudo com 30 cirurgiões bucomaxilo-faciais e três diferentes materiais de suturas (softgut, ácido poliglcólico e poligalactina 910). Este levantamento revelou uma maior preferência no uso de suturas absorvíveis que durasse de 5 a 14 dias nas suturas bucais ${ }^{16}$. E neste aspecto nenhum dos materiais por eles testados não se apresentou satisfatório. De acordo com estudos ${ }^{4}$ a absorção do poliglecaprone 25 é completa entre 91 e 119 dias após implantação. No nosso estudo o fio permaneceu ainda no $28^{\circ}$ dia de pós-operatório. No entanto, para suturas bucais e internas sugerimos o desenvolvimento de um fio que esteja presente apenas no período de duas semanas (14 dias) que compreende durante a fase crítica da cicatrização e reparação de tecidos.

\section{Conclusões}

Clinicamente não houve diferença entre os fios de sutura estudados. Histopatologicamente suturas externas realizadas com nylon induziram menor reação tecidual, enquanto que nas suturas internas este fio contribuiu para perpetuar a reação tecidual. As suturas externas realizadas com poliglecaprone 25 apresentaram maior reação tecidual, e suturas internas realizadas com o mesmo fio a reação tecidual declinou na medida em que o fio estava sendo absorvido.

\section{Referências}

1. Valiati R, Lemes CHJ, Machado IG, Zambrano CBB. Avaliação clínica e histológica do reparo da pele de suíno com o uso de zíper cirúrgico (woundcloster ${ }^{\circledR}$ ). Rev Bras Cir Implant.2000; 28(7):37-44.

2. Peterson LJ. In: Peterson LJ, Ellis E, Hupp JR, Tucker MR. Cirurgia Oral e Maxilofacial Contemporânea. Tradução da 4 ed. Rio de Janeiro: Elsevier; 2005.

3. Hering FLO, Gabor S, Rosenberg D. Bases técnicas e teóricas de fios de sutura. 1 ed. São Paulo: Roca; 1993.

4. Bezwada RS, Jamiolkowski DD, Lee IY, Agarwal V, Persivale J, Trenka-Benthin S, Erneta M, Suryadevara J, Yang A, Liu S. Monocryl suture, a new ultra-pliable absorbable monofilament suture. Biomaterials. 1995; 16(15):1141-8.

5. Nary Filho H, Matsumoto MA, Batista AC, Lopes LC, Góes FCGS, Consolaro A. Comparative study of tissue reactivity to poliglecaprone 25 , polygalactin 910 and 
polytetraflorethylene suture materials in rats. Braz Dent J. 2002; 13(2): 86-91.

6. Nogueira RLM, Meneses JR JMS, Os fios de sutura em cirurgia bucal. Rev Cearense Odontol.2001; 2(1):73-81.

7. Nary Filho H, Okamoto T, Padovan LEM. Estudo comparativo da resposta tecidual a fios de sutura de Poligalactina 910 e Poliglecaprone 25 em subcutâneo de ratos. Rev Fac Odontol Bauru. 1997; 5(3/4):45-50.

8. Hendler K. Basic Principles of treatment: hard and soft tissue. In: Fonseca RJ. Oral and maxillofacial surgery. v.3. Philadelphia: Saunders Company; 2000. p.25-44.

9. Okamoto T, Barbieri CM, Okamoto R, Gabrielli MFR. Estudo histomorfológico comparativo entre os fios de polibutester e poliéster em sutura superficial da mucosa bucal de ratos. Rev Fac Odontol Lins. 1997; 10(1):24-8.

10. Cuffari L. Considerações gerais em odontologia dos fios de sutura. J Bras Odontol Clin. 1997: 1(1):43-7.

11. Castro HL, Okamoto T, Castro AL. Reação tecidual a alguns fios de sutura Avaliação histológica em ratos. Rev Fac Odontol Araçatuba. 1974; 3:101-11.

12. Weismann R, Brito JHM. Resposta tecidual frente a diferentes fios de sutura implantados na língua de ratos. Rev Odonto Cienc 1993;8(16):19-31.

13. Bernstein RM, Rassman WR, Rashid N. A new suture for hair transplantation: poliglecaprone 25. Dermatol Surg. 2001; 27(1):5-11.
14. Molea G,Schonauer ,Bifulco G, D’Angelo D. Comparative study on biocompatibility and absorption times of three absorbable monofilament suture materials (Polydioxanone, Poliglecaprone 25, Glycomer 631). Br J Plast Surg. 2000; 53(2):137-41.

15. Trimbos JB, Niggebrugge A, Trimbos R, Van Rijssel EJ. Knotting abilities of a new absorbable monofilament suture: poliglecaprone 25 (Monocryl). Eur J Surg. 1995; 161(5):319-22.

16. Shaw RJ, Negus TW, Mellor TK. A prospective clinical evaluation of the longevity of reabsorbable sutures in oral mucosa. Br J Oral Maxillofac Surg. 1996;34: 252-4.

\section{Agradecimentos}

O presente estudo foi realizado com o apoio do Conselho Nacional de Desenvolvimento Científico e Tecnológico FACEPE - CNPq Brasil.

Este trabalho foi realizado nos laboratórios da UFRPE que nos disponibilizaram as instalações para a realização das cirurgias experimentais, coleta dos materiais, processamento, leitura e fotografias das lâminas.

Agradecemos ainda a oportunidade de desenvolver um trabalho de pesquisa com uma equipe séria e comprometida com os avanços da ciência.

\section{Correspondência:}

Prof. Dr. Belmiro Cavalcanti do Egito Vasconcelos

Av. Gal. Newton Cavalcanti, 1650

Camaragibe Pernambuco

54.753-220

belmiroc@terra.com.br

(81) 3458-2867
Conflito de interesse: nenhum. Fonte de financiamento: FACEPE - CNPq

Recebimento: 09/03/2005

Revisão: 04/04/2005

Aprovação: 09/05/2005

\section{Como citar este artigo:}

Ribeiro CMB, Silva Júnior VA, Silva Neto JC, Vasconcelos BCE. Estudo clínico e histopatológico da reação tecidual às suturas interna e externa dos fios monofilamentares de nylon e poliglecaprone 25 em ratos. Acta Cir Bras. [periódico na internet] 2005 Jul-Ago;20(4). Disponível em URL: http://www.scielo.br/acb

* Figuras coloridas disponíveis em http://www.scielo.br/acb 